\title{
Osteoid Osteoma in the Lateral Malleolus, a Case Report
}

\author{
Tan Wei How, Bahari Syah Irwan \\ KPJ Healthcare University College, Nilai, Malaysia \\ Email: tanweihow@yahoo.com.my
}

How to cite this paper: How, T.W. and Irwan, B. (2021) Osteoid Osteoma in the Lateral Malleolus, a Case Report. Journal of Biosciences and Medicines, 9, 16-21. https://doi.org/10.4236/jbm.2021.97003

Received: May 5, 2021

Accepted: July 5, 2021

Published: July 8, 2021

Copyright $\odot 2021$ by author(s) and Scientific Research Publishing Inc. This work is licensed under the Creative Commons Attribution International License (CC BY 4.0).

http://creativecommons.org/licenses/by/4.0/

\begin{abstract}
Osteoid osteoma is a benign bone tumor that is commonly seen in males in their second and third decade of life. The tumor commonly occurs in long bones (proximal femur and tibia) and rarely in the spine, hands and feet. It presents with bone pain worsening at night and responds well to nonsteroidal anti-inflammatory drugs. It is usually treated conservatively but sometimes with surgery if medical treatment fails. We present a case of 19-year-old girl, who presented with mild pain over lateral aspect of right ankle for 6 months duration. The pain was provoked by sporting activities, and was initially relieved by analgesics, until recently, hence her presentation. CT scan was done and showed a well-defined central nodule of bone. She had an open excisional biopsy, and the histology showed a diagnosis of osteoid osteoma. Post-operative healing was uneventful, the fracture united after 6 weeks and she was able to ambulate without any pain 3 months post-surgery.
\end{abstract}

\section{Keywords}

Benign, Bone Tumour, Excisional Biopsy, Lateral Malleolus, Osteoid Osteoma

\section{Introduction}

Osteoid osteoma is a small discrete benign bone tumor that is usually solitary but can be multiple. It presents as a painful bone lesion in the young population with $80 \%$ presenting before the age of 30 , more common in males than in females (2:1 ratio) [1] [2]. It is commonly found in the lower extremity, spine, hand and rarely on the foot. It can present as painful bone swelling or lesions, painful scoliosis, growth disturbance and flexion contractures. Osteoid osteoma has distinctive radiographic findings with intensely reactive bone around a radiolucent nidus. The classic radiographic appearance is an oval, radiolucent cen- 
tral focus smaller than $2 \mathrm{~cm}$ with surrounding reactive sclerosis [3] [4]. Computerized tomography scan might help in identifying the location and size of nidus. The size of bone tumor is usually less than $1.5 \mathrm{~cm}$, if greater than $2 \mathrm{~cm}$, osteoblastoma has to be ruled out. Most cases of osteoid osteoma are self-limiting, and non-surgical management is the first line of treatment, whereas osteoblastoma is progressive and aggressive, and surgical treatment is always indicated. We present a case of osteoid osteoma in the lateral malleolus which was successfully treated surgically.

\section{Case Report}

A healthy 19-year-old girl, who presented with mild pain over lateral aspect of right ankle of 6 months duration (informed consent obtained). The pain usually occurred after sport exercise activities and usually subsided within few days of painkiller administration. Two weeks prior to admission, she presented with severe right ankle pain following a trivial twist over the same ankle. She was still able to ambulate but the pain did not improve with painkillers. On examination, there was minimal swelling and tenderness over the lateral malleolus. There was full range of motion over the ankle and no instability of the ankle was elicited.

$\mathrm{X}$ ray (Figure 1 (a) and Figure $1(\mathrm{~b})$ ) was done and showed a lytic lesion about $1.5 \mathrm{~cm}$ over the inner third of the right lateral malleolus. CT scan (Figure 2(a) and Figure 2(b)) was done and showed a well-defined central nodule of woven bone and osteoid with osteoblastic rimming bone lesion also known as nidus over medial aspect of lateral malleolus, no fracture line seen.

MRI (Figure 3(a) and Figure 3(b)) showed a well-defined bony lesion mimicking oedema over the medial aspect of the lateral malleolus. She was advised to take NSAIDs for 2 weeks but pain did not improve, hence a decision to proceed with excisional biopsy of the tumor.

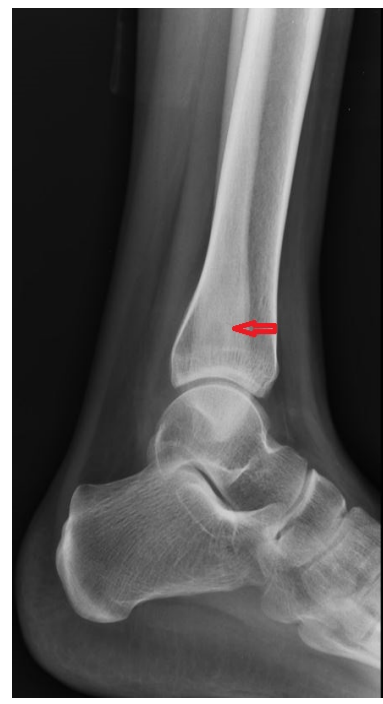

(a)

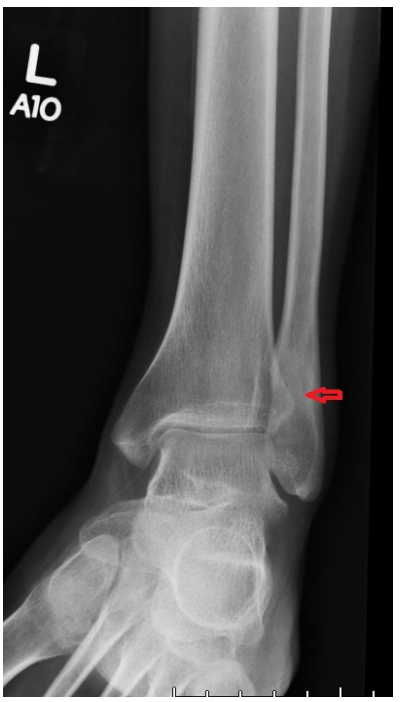

(b)

Figure 1. X ray of the left ankle showed a lytic lesion about $1.5 \mathrm{~cm}$ over the inner third of the right lateral malleolus. 


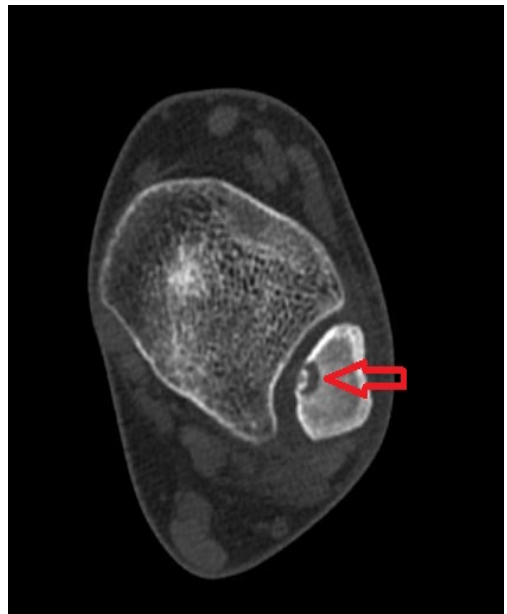

(a)

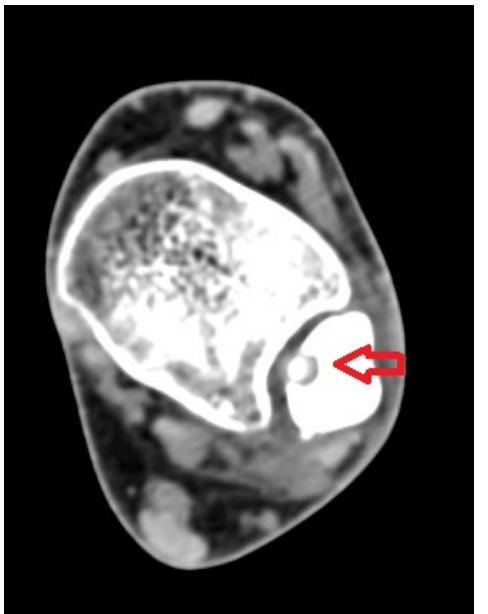

(b)

Figure 2. CT scan of ankle showed nidus over medial aspect of lateral malleolus.

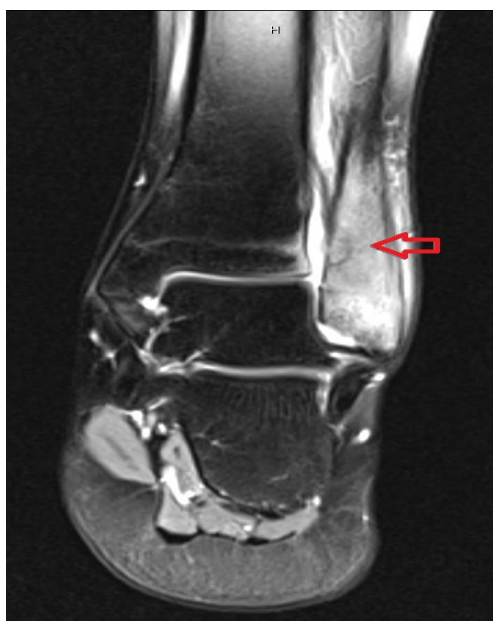

(a)

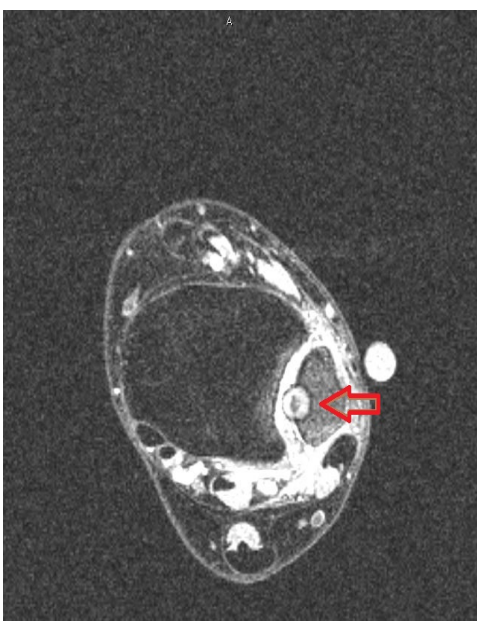

(b)

Figure 3. MRI showed a well-defined bony lesion mimicking oedema over the medial aspect of the lateral malleolus.

Intra-operatively, ankle scope performed which showed that both anterior inferior tibiofibular ligament and posterior inferior tibiofibular ligament were intact. Syndesmotic joint was stable. Part of the lytic lesion could be seen through ankle arthroscopy but the lesion could not be fully resected through this mean. Hence, an open biopsy was carried out with fibula osteotomy. The bone lesion was about $1 \mathrm{~cm}$ in depth which was less than one third of the lateral malleolus diameter and is presented as Figure 4.

After surgical resection and curettage was done, the fibula was reduced and lag screws and a tight rope were applied (Figure 5(a) and Figure 5(b)). On follow up, the histology (Figure 6) showed osteoid osteoma and the fracture united after 6 weeks. Patient was able to ambulate without any pain after 3 months post-surgery. 


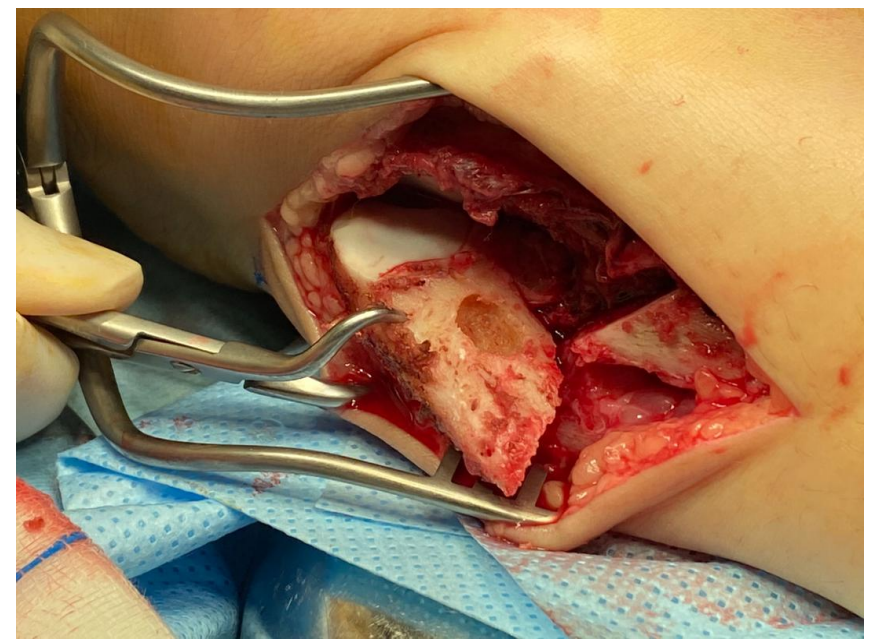

Figure 4. Picture showing lytic cyst over inner aspect of lateral malleolus.

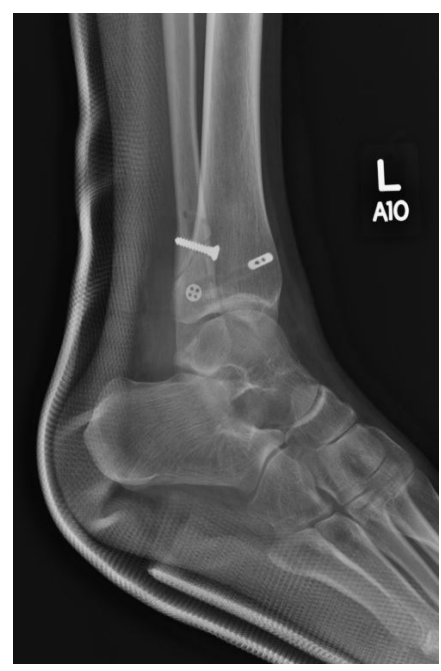

(a)

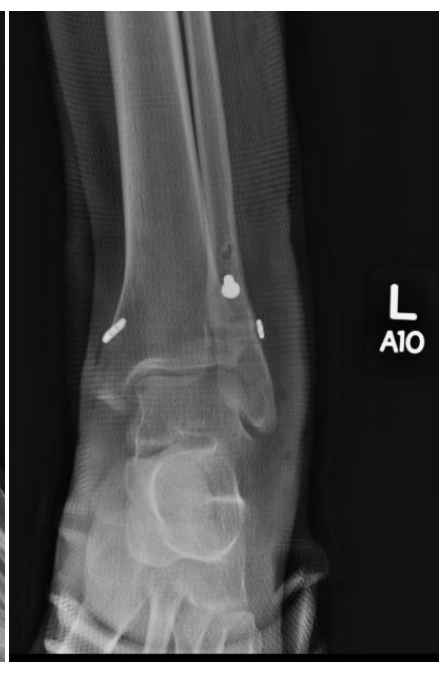

(b)

Figure 5. $\mathrm{x}$ ray of the ankle post lag screws and tight rope.

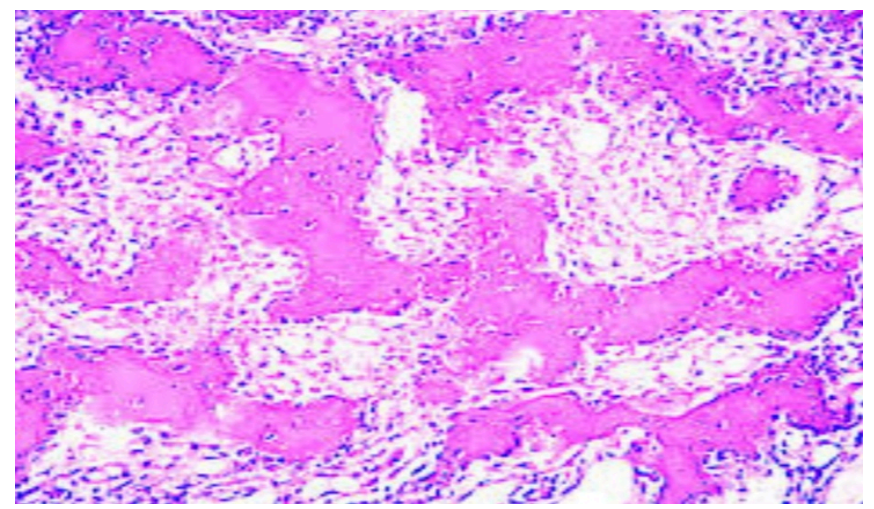

Figure 6. HPE showed multiple fragments of bone tissue composed of anastomosing and irregular woven bone with variable area of mineralization. Scattered multinucleated cells are seen in the sclerotic stroma. 


\section{Discussion}

Osteoid osteoma is a benign bone tumor which is self-limiting and resolves in 5 to 7 years. The $1^{\text {st }}$ line of treatment was pain management. More than $50 \%$ of cases can be treated with NSAIDs alone. Surgery is indicated if there is failure of medical management, periarticular lesions which increase the risk of cartilage injury causing premature degenerative disease, presents of spinal lesion and suspicious of malignancy. In our case, her sport activities were affected by the bony lesion and the pain did not improved with medical management. Choices of surgery can be percutaneous radiofrequency ablation or open surgical resection and curettage depending on complete marginal resection of the nidus. Radiofrequency ablation (RFA) since its introduction for the treatment of osteoid osteoma in 1992, RFA has quickly become a widely accepted treatment method [5] [6]. Many surgeons consider RFA as the treatment of choice for osteoid osteomas as it is a simple, minimally invasive procedure with clinical success rates of 89\% - 95\% [6] [7]. This was however not an option for this case due to the position of the bony lesion which would be difficult to reach by the radiofrequency probe. For bony lesions at difficult areas, open resection with bony osteotomy might be needed. Surgical excision aided by intraoperative fluoroscopy is the gold standard in the treatment. Besides en bloc excision, a burr-down technique has been described where the sclerotic cortex is burred up to the nidus, the cavity curetted and the wall is again burred thoroughly [8]. In our case, the size of the lesion was small (around $1 \times 1.5 \mathrm{~cm}$ ), which was around $1 \times 1.5 \mathrm{~cm}$ which is less than one third of the fibula diameter, hence no bone graft was required. In those big bony lesions, bone grafts may be required to prevent stress fracture and recurrence.

For radiographic modalities, $\mathrm{CT}$ scan is the best choice for diagnosis of osteoid osteoma compared to MRI [3]. Although MRI is more superior in outline intramedullary and soft tissue changes, this may cause a misleading aggressive appearance of these benign tumours. Small nidus can be difficult to detect on MRI due to the similar signal intensities of the nidus to the adjacent cortex. Multiple studies have reported similar limitation of MRI compared to CT scan for detection of nidus [9] [10]. In our case, MRI showed a well-defined bony lesion mimicking oedema rather than nidus.

\section{Conclusion}

Osteoid osteoma is a small discrete benign bone tumor presenting with bone pain. Most of the cases can be treated conservatively as they are often self-limiting. Surgery is only indicated for big lesions or after conservative management has failed.

\section{Conflicts of Interest}

The authors declare no conflicts of interest regarding the publication of this paper. 


\section{References}

[1] Kransdorf, M.J., Stull, M.A., Gilkey, F.W. and Moser, R.P. (1991) Osteoid Osteoma. Radio Graphics, 11, 671-696. https://doi.org/10.1148/radiographics.11.4.1887121

[2] Scehajowicz, F. and Lemos, C. (1970) Osteoid Osteoma and Osteoblastoma: Closely Related Entities of Osteoblastic Derivation. Acta Orthopaedica Scandinavica, 41, 272-291. https://doi.org/10.3109/17453677008991514

[3] Chai, J.W., Hong, S.H. and Choi, J.-Y. (2010) Radiologic Diagnosis of Osteoid Osteoma: From Simple to Challenging Findings. Radio Graphics, 30, 737-749. https://doi.org/10.1148/rg.303095120

[4] Ciftdemir, M., Tuncel, S. and Usta, U. (2015) Atypical Osteoid Osteomas. European Journal of Orthopaedic Surgery \& Traumatology, 25, 17-27. https://doi.org/10.1007/s00590-013-1291-1

[5] Rosenthal, D.I., Alexander, A., Rosenberg, A.E. and Springfield, D. (1992) Ablation of Osteoid Osteomas with a Percutaneously Placed Electrode: A New Procedure. Radiology, 183, 29-33. https://doi.org/10.1148/radiology.183.1.1549690

[6] Motamedi, D., Learch, T.J. and Ishimitsu, D.N. (2009) Thermal Ablation of Osteoid Osteoma: Overview and Step-By-Step Guide. Radio Graphics, 29, 2127-2141. https://doi.org/10.1148/rg.297095081

[7] Lindner, N.J., Ozaki, T., Roedl, R., Gosheger, G., Winkelmann, W. and Wörtler, K. (2001) Percutaneous Radiofrequency Ablation in Osteoid Osteoma. The Journal of Bone and Joint Surgery. British Volume, 83-B, 391-396. https://doi.org/10.1302/0301-620X.83B3.0830391

[8] Lee, E.H., Shafi, M. and Hui, J.H.P. (2006) Osteoid Osteoma. Journal of Pediatric Orthopaedics, 26, 695-700. https://doi.org/10.1097/01.bpo.0000233807.80046.7c

[9] Davies, M., Cassar-Pullicino, V.N., Davies, A.M., McCall, I.W. and Tyrrell, P.N.M. (2002) The Diagnostic Accuracy of MR Imaging in Osteoid Osteoma. Skeletal Radiology, 31, 559-569. https://doi.org/10.1007/s00256-002-0546-4

[10] Assoun, J., Richardi, G. and Railhac, J.J. (1994) Osteoid Osteoma: MR Imaging versus CT. Radiology, 191, 217-223. https://doi.org/10.1148/radiology.191.1.8134575 